\title{
Feasibility study of antiseptic gel formulations containing essential oils of Cymbopogon citratus (DC.) stapf. and of Caryophyllus aromaticus L.
}

\author{
Caroline $\operatorname{Rohr}^{\mathrm{a}, 2}$, Layane Lenardon Vinciguerra*b, ${ }^{2}$, Graziela Heberlé ${ }^{\mathrm{a}}$ \\ ${ }^{a}$ Centro Universitário Univates, Av. Avelino Talini,171, Lajeado-RS, Brazil. \\ ${ }^{b}$ Universidade Federal do Rio Grande do Sul, Faculdade de Farmácia, Av.Ipiranga, 2752, Porto Alegre-RS, Brazil
}

*Corresponding author: layane.farmacia@hotmail.com

\begin{abstract}
In recent years we have seen an increase in the pursuit of products and active compounds of natural origin by the pharmaceutical industry. Additionally, there is a need for creation of new market products such as antiseptics, used to prevent or decrease risk of infection by inhibiting the proliferation of microorganisms. The objective of this study was to produce two antiseptic gels incorporating into each of them, individually, lemon grass (Cimbopogon citratos (DC.) Stapf.) essential oil and clove (Caryophillus aromaticus L.) essential oil, subsequently evaluating antimicrobial activity by minimum inhibitory concentration (MIC) test. Oils and gels were tested in parallel and showed a similar profile that can be observed in the inhibition concentration. This was a preliminary study that merits further investigation, which may include stability testing and evaluation of lower concentrations of oils incorporated into the gel base.
\end{abstract}

Keywords: Essential oil. Gel formulation. MIC. Viability.

\section{Introduction}

Brazil is a country noted for its vast plant biodiversity and this aroused the interest of pharmaceutical industry that intent on developing new products of vegetal origin. The use of plants in cosmetics has advanced scientific study of plant active compounds for topical application. There is a greater preference among general population for these types of product, known as "natural products". Plants must be subjected to some form of extraction process of the substances of interest to enable their use for therapeutic purposes. (Mittermeier et al, 2005; Elansary et al, 2015).

Extraction of essential oils from plants is carried out through a process of steam distillation, whereby oil is entrained by the steam produced from water. Essential oils generally have a pleasant aroma and are widely used in medicine, cooking, and mainly in cosmetics, due to their antiseptic and anti-inflammatory activity, and soothing effect. Clove essential oil is extracted from flower buds that contain eugenol as the main compound. The oil is a colourless to pale yellow liquid, with a characteristic odour, being responsible for the antibacterial and antifungal activities. Lemongrass essential oil is found in plant leaves and has a strong smell of lemon, being citral its main component.
It is of great importance in perfume and food industries, and also presents proof of scientific efficacy for some microorganisms, and has diversified uses in many countries such as China, Nigeria, and Indonesia, among others. (Sartor et al, 2011; Munir et al, 2014; Sebaal et al, 2015; Boukhatem et al, 2014).

Among the most widely used techniques for testing antimicrobial activity of essential oils, MIC is the methodology proposed by NCCLS (National Committee for Clinical Laboratory Standards) that set standards for antimicrobial susceptibility tests. This study aimed to produce two antiseptic gels containing essential oils - one with lemongrass essential oil and the second with clove essential oil, and performing evaluation of antimicrobial activity of these gels.

\section{Methodology}

Obtaining the plants

Fresh lemongrass leaves were collected in the city of Lajeado/RS, Brazil, at around 7 a.m. in mild temperature conditions and with no rain. A plant sample was subsequently sent for identification and specimen preparation (number 3337) to the Botany Laboratory of UNIVATES University Centre. 
Cloves were purchased from the commercial supplier 'Flores e Ervas', located in Sao Paulo/SP, Brazil.

\section{Extraction of essential oils}

Essential oils were obtained by hydrodistillation process by steam distillation, with water as solvent. The traditional method was used for cloves and a condenser was used for lemongrass. Lemongrass leaves were cut using scissors, whilst clove flower buds were used intact. The steam distillation system was turned off after 4 h 30 min of extraction. (Farmacopéia Brasileira IV, 1989).

\section{Biological testing}

Test for antimicrobial activity was conducted using ATCC (American Type Culture Collection) strains of Pseudomonas aeruginosa (ATCC 27853) and Escherichia coli (ATCC 33592), gram-negative bacteria, and Staphylococcus aureus (ATCC 25923) grampositive bacteria. The fungus Candida albicans (ATCC 10231) was also used. (Kerr, 2005).

\section{Minimum inhibitory concentration}

The microrganisms were inoculated onto the surface of a Petri dish containing nutrient agar and the fungus onto a dish containing Sabouraud agar. Bacteria and fungus that subsequently grew were inoculated in saline solution and adjusted to $0.5 \mathrm{McFarland}$ standard. $100 \mu \mathrm{L}$ of this solution was then added to a tube containing either Casein Soya Broth for bacteria or Sabouraud Dextrose Broth for yeast, thereby forming inoculum suspensions, being $100 \mu \mathrm{L}$ transferred to each plate well. (NCCLS, 2003).

This procedure followed the microdilution method in microwell plates, as shown in Figure 1. In the first line, characterized by letter $\mathrm{A}$, is the highest concentration, thus samples were diluted to the line represented by letter F, which contains the lowest concentration. Line $G$ was destined to control sample of microorganisms, and line $\mathrm{H}$ to control sample of culture media. (NCCLS, 2003)

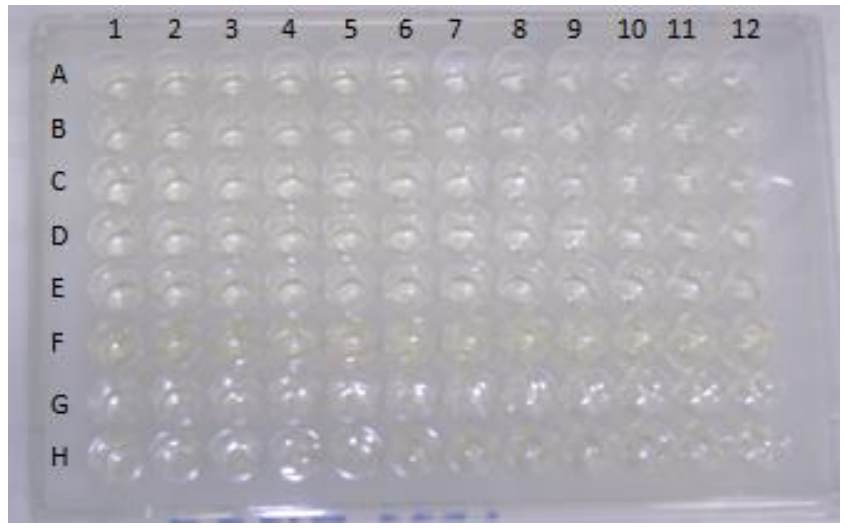

Figure 1. Model of 96 microwell plate.

Lemongrass and clove oils were tested in the first MIC investigation according to Figure 2, at the concentration of $20 \mu \mathrm{g} / \mu \mathrm{L}$ in the first well, 10 $\mu \mathrm{g} / \mu \mathrm{L}$ in the second well, $5 \mu \mathrm{g} / \mu \mathrm{L}$ in the third well, $2.5 \mu \mathrm{g} / \mu \mathrm{L}$ in the fourth well, $1.25 \mu \mathrm{g} / \mu \mathrm{L}$ in the fifth well, and $0.625 \mu \mathrm{g} / \mu \mathrm{L}$ in the sixth well, diluted in DMSO (Dimethyl sulfoxide). Chloramphenicol and nystatin were used as antibiotics standards, and DMSO was used as blank sample. (NCCLS, 2003).

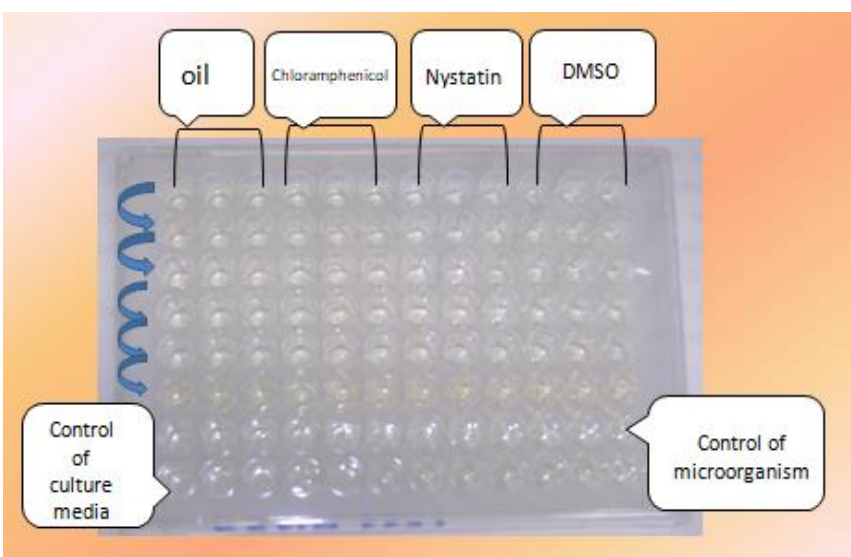

Figure 2. Representation of MIC analysis from lemongrass and clove oils.

A gel formulation containing $20 \%$ of essential oils was tested with the following concentrations (in oil) in microwell plates as shown in Figure 3: $4 \mu \mathrm{g} / \mu \mathrm{L}$ in the first well, $2 \mu \mathrm{g} / \mu \mathrm{L}$ in the second well, $1 \mu \mathrm{g} / \mu \mathrm{L}$ in the third well, $0.5 \mu \mathrm{g} / \mu \mathrm{L}$ in the fourth well, $0.25 \mu \mathrm{g} / \mu \mathrm{L}$ in the fifth well, and $0.125 \mu \mathrm{g} / \mu \mathrm{L}$ in the sixth well. The gel base formulation itself was also tested and used with propylene glycol in the same quantity to dilute the oils, tested as blank. (NCCLS, 2003). 
Drug Anal Res, 2017; 02, xx

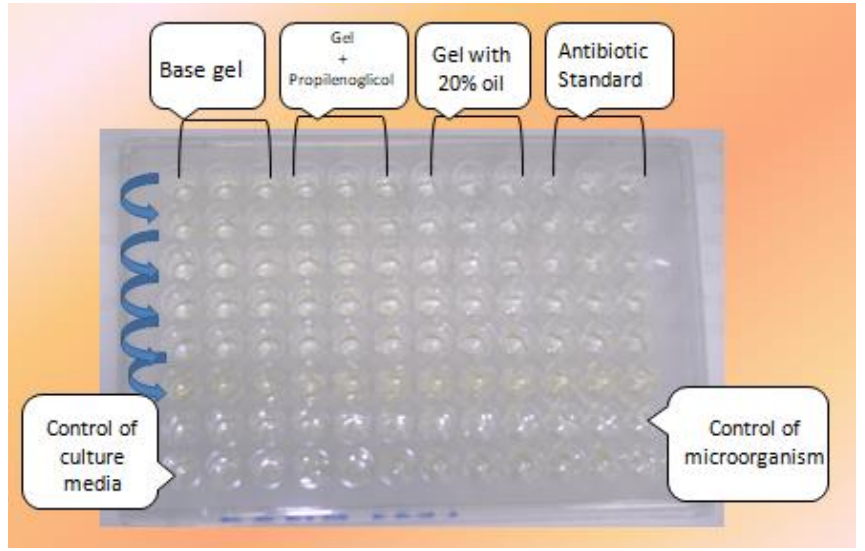

Figure 3. Representation of MIC analysis of gel formulation containing $20 \%$ of the obtained oils.

The microwell plates were incubated at $36{ }^{\circ} \mathrm{C}+/-1{ }^{\circ} \mathrm{C}$ for $48 \mathrm{~h}$ for bacteria and for $72 \mathrm{~h}$ at $25^{\circ} \mathrm{C}$ for fungus. MIC was demonstrated through turbidity in culture media. Plates were sprayed with sterile triphenyl tetrazolium chloride aqueous solution, which turns red at the presence of microbial growth. All MIC tests were performed in triplicate using a 96 microwell plate for each microorganism. (Kerr, 2005).

\section{Preliminary test of antimicrobial activity}

Swab samples were collected from hands that had not been washed for at least 2 hours. Samples were subsequently cultivated in Plate Count Agar and Sabouraud Agar, incubated at 36 ${ }^{\circ} \mathrm{C}$ for $48 \mathrm{~h}$ and $25^{\circ} \mathrm{C}$ for $72 \mathrm{~h}$, respectively. The gel formulation was applied to these same dirty hands and allowed to act for 5 minutes before repeating the procedure for swab samples collection and cultivation.).

\section{Preparation of formulations}

Methylparaben (Nipagin $®), \quad$ solubilized with propylene glycol, and Carbopol ${ }^{\circledR}$ were added to a container of distilled water for preparation of the gel base (Table 1). This mixture was left to stand for $24 \mathrm{~h}$, being after that stirred and neutralized with triethanolamine until forming a gel. Oils were incorporated into the gel base, having first been dissolved with sufficient amount of propylene glycol. In this way, gel formulations containing lemongrass oil and clove oil were obtained.

\begin{tabular}{cc} 
Table 1. Gel formulation. & \\
\hline Components & Quantity \\
\hline Carbopol® & $0.8 \mathrm{~g}$ \\
Nipagin ${ }^{\circledR}$ & $0.2 \mathrm{~g}$ \\
Propylene Glycol & $0.1 \mathrm{~g}$ \\
Essential oil & $20 \%$ \\
Triethanolamine & $0.2 \mathrm{~g}$ \\
Water & q.s.p. $100 \mathrm{~mL}$ \\
\hline
\end{tabular}

\section{Results and discussion}

Oil yeld

Clove essential oil yield was $8.63 \%$ while lemongrass oil yield was $0.49 \%$.

\section{Determination of $p H$}

The $\mathrm{pH}$ (6.5) of each formulation was maintained after addition of essential oils to the gel formulations.

\section{Evaluation of antimicrobial activity}

MIC testing was performed in parallel between oils and gels. As can be seen in Table 2, lemongrass oil inhibited Staphylococcus aureus at the concentrations of $20,10,5$ and $2.5 \mu \mathrm{g} / \mu \mathrm{L}$, but not at the concentrations of $1.25 \mu \mathrm{g} / \mu \mathrm{L}$ and 0.625 $\mu \mathrm{g} / \mu \mathrm{L}$; it inhibited Escherichia coli at the concentrations of $20,10,5$ and $2,5 \mu \mathrm{g} / \mu \mathrm{L}$, but not at the concentrations of 1.25 and $0.625 \mu \mathrm{g} / \mu \mathrm{L}$; lemongrass oil inhibited Pseudomonas aeruginosa at the concentration of $20 \mu \mathrm{g} / \mu \mathrm{L}$, but not at the concentrations of $10,5,2.5,1.25$ and $0.62 \mu \mathrm{g} / \mu \mathrm{L}$, and inhibited Candida albicans at the concentrations of $20,10,5,2.5$ and $1.2 \mu \mathrm{g} / \mu \mathrm{L}$ but not at the concentration of $0.625 \mu \mathrm{g} / \mu \mathrm{L}$. Clove oil inhibited Staphylococcus aureus and Pseudomonas aeruginosa at the concentrations of 20, 10 and 5 $\mu \mathrm{g} / \mu \mathrm{L}$, but not at the concentrations of $2.5,1.25$ and $0.625 \mu \mathrm{g} / \mu \mathrm{L}$; clove oil inhibited Escherichia coli and Candida albicans at the concentrations of $20,10,5$ and $2.5 \mu \mathrm{g} / \mu \mathrm{L}$, but not at the concentrations of 1.25 and $0.625 \mu \mathrm{g} / \mu \mathrm{L}$. 
Table 2. Inhibition of microbial growth by essential oils.

\begin{tabular}{rrrrrrrrrrrr}
\hline $\mathrm{L}$ & $\mathrm{C}$ & $\mathrm{L}$ & $\mathrm{C}$ & $\mathrm{L}$ & $\mathrm{C}$ & $\mathrm{L}$ & $\mathrm{C}$ & $\mathrm{L}$ & $\mathrm{C}$ & $\mathrm{L}$ & $\mathrm{C}$ \\
$20 \mu \mathrm{g} / \mu \mathrm{L}$ & $10 \mu \mathrm{g} / \mu \mathrm{L}$ & $5 \mu \mathrm{g} / \mu \mathrm{L}$ & $2,5 \mu \mathrm{g} / \mu \mathrm{L}$ & $1,25 \mu \mathrm{g} / \mu \mathrm{L}$ & $0,625 \mu \mathrm{g} / \mu \mathrm{L}$ \\
$\mathrm{SA}+$ & + & + & + & + & + & + & - & - & - & - & - \\
$\mathrm{EC}+$ & + & + & + & + & + & + & + & - & - & - & - \\
$\mathrm{PA}+$ & + & - & + & - & + & - & - & - & - & - & - \\
$\mathrm{CA}+$ & + & + & + & + & + & + & + & + & - & - & - \\
\hline
\end{tabular}

$\mathrm{L}=$ Lemongrass essential oil $; \mathrm{C}=$ Clove essential oil $; \mathrm{SA}=$ Staphylococcus aureus $; \mathrm{EC}=$ Escherichia coli $; \mathrm{PA}=$ Pseudomonas aeruginosa $; \mathrm{CA}$ $=$ Candida albicans $;(+)=$ inhibition of microorganisms; $(-)=$ no inhibition of microorganisms.

Table 3 shows the inhibitory concentrations of gels containing the oils, where it can be seen that lemongrass gel inhibited Staphylococcus aureus and Escherichia coli microorganisms at the concentrations of 4, 2 and 1 $\mu \mathrm{g} / \mu \mathrm{L}$, but not at the concentrations of $0.5,0.25$ and $0.125 \mu \mathrm{g} / \mu \mathrm{L}$. There is an absence of inhibition of Pseudomonas aeruginosa, with no inhibitive action occurring at any concentration tested. Candida albicans was inhibited at the concentrations of 4 and $2 \mu \mathrm{g} / \mu \mathrm{L}$, but there was no inhibition at the concentrations of 1 , $0.5,0.25$ and $0.125 \mu \mathrm{g} / \mu \mathrm{L}$. Clove gel inhibited all four microorganisms tested at the concentrations of 4,2 and $1 \mu \mathrm{g} / \mu \mathrm{L}$, but didn't inhibit at the concentrations of $0.5,0.25$ and $0.125 \mu \mathrm{g} / \mu \mathrm{L}$.

Table 3. Inhibitory concentrations of gels containing the oils.

\begin{tabular}{rrrrrrrrrrrr}
\hline $\mathrm{L}$ & $\mathrm{C}$ & $\mathrm{L}$ & $\mathrm{C}$ & $\mathrm{L}$ & $\mathrm{C}$ & $\mathrm{L}$ & $\mathrm{C}$ & $\mathrm{L}$ & $\mathrm{C}$ & $\mathrm{L}$ & $\mathrm{C}$ \\
$4 \mu \mathrm{g} / \mu \mathrm{L}$ & $2 \mu \mathrm{g} / \mu \mathrm{L}$ & & $1 \mu \mathrm{g} / \mu \mathrm{L}$ & $0,5 \mu \mathrm{g} / \mu \mathrm{L}$ & $0,25 \mu \mathrm{g} / \mu \mathrm{L}$ & $0,125 \mu \mathrm{g} / \mu \mathrm{L}$ & \\
\hline $\mathrm{SA}+$ & + & + & + & + & + & - & - & - & - & - & - \\
$\mathrm{EC}+$ & + & + & + & + & + & - & - & - & - & - & - \\
$\mathrm{PA}-$ & + & - & + & - & + & - & - & - & - & - & - \\
$\mathrm{CA}+$ & + & + & + & - & + & - & - & - & - & - & - \\
\hline
\end{tabular}

L = Lemongrass essential oil $; \mathrm{C}=$ Clove essential oil $; \mathrm{SA}=$ Staphylococcus aureus $; \mathrm{EC}=$ Escherichia coli $; \mathrm{PA}=$ Pseudomonas aeruginosa $; \mathrm{CA}$ $=$ Candida albicans $;(+)=$ inhibition of micro-organisms; $(-)=$ no inhibition of micro-organisms.

Looking at Tables 2 and 3 it's verified that both gel formulations and pure oils present differentiated inhibition profiles, based on the microorganism type. However, we can note that the gel formulation with oil at the concentration of 4 $\mu \mathrm{g} / \mu \mathrm{L}$ shows the same inhibition profile as the pure oil at $5 \mu \mathrm{g} / \mu \mathrm{L}$. Additionally, the pure oils at the concentration of $2.5 \mu \mathrm{g} / \mu \mathrm{L}$ seem to have less potential for inhibition when compared to the gel formulation with the concentration of $2 \mu \mathrm{g} / \mu \mathrm{L}$, with the exception of Pseudomonas aeruginosa. We found that lemongrass oil at the concentration of $1.25 \mu \mathrm{g} / \mu \mathrm{L}$ inhibited only the fungus Candida albicans, whereas gel formulations with the concentration of $1 \mu \mathrm{g} / \mu \mathrm{L}$ inhibited all microorganisms except for Candida albicans and Pseudomonas aeruginosa. Therefore, our data suggest that in general, formulations containing the oils in a gel base present better inhibitory potential in relation to the pure oils when tested in microorganisms. Chloramphenicol antibiotic and nystatin antifungal showed inhibition against bacteria and fungus, respectively, on the test.

\section{Preliminary test of antiseptic activity}

As shown in Figure 4, swab smear test demonstrated growth on the dishes for samples taken from unwashed hands. When tested again 
after application of lemongrass and clove gels, it resulted in a complete absence of growth.

Figure 4.A. Culture from an unwashed hand before use of lemongrass gel; B. Culture from the same hand after use of lemongrass gel; C. Culture from an unwashed hand before use of clove gel; D. Culture from the same hand after use of clove gel.

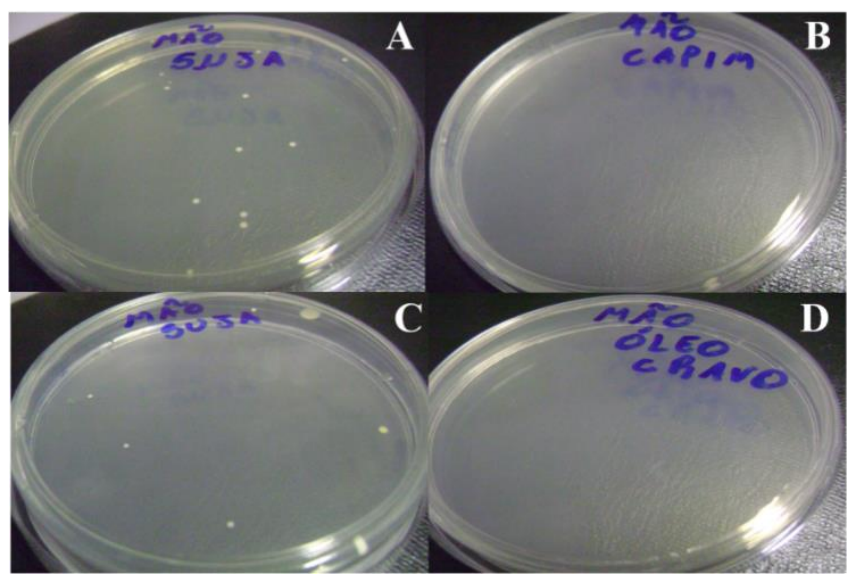

Figure 4. A. Culture from an unwashed hand before use of lemongrass gel; B. Culture from the same hand after use of lemongrass gel; C. Culture from an unwashed hand before use of clove gel; D. Culture from the same hand after use of clove gel.

\section{Conclusions}

Development of an antiseptic gel formulation using lemongrass and clove essential oil is a viable alternative, as antimicrobial activity could have been verified for the concentrations of the oils tested, with this activity also being maintained after incorporation into gel. This activity was verified through the results of swab tests and MIC analysis. In addition, MIC data suggest that in general, both gel formulations presented better inhibitory potential in the microorganisms tested in suspension when compared to the pure oils.

Based on the obtained results, the use of these gels as antiseptic agents for human skin can be suggested. It should be noted that this is a preliminary study that merits further investigation into the development of these products and may progress to stability testing and evaluation of lower concentrations of the oils to be incorporated into gel base.

\section{Acknowledgments}

MHM and ACS are grateful to CAPES and PIBIT/CNPq/UFSM, respectively, for the scholarship. CBS thanks the financial support by $\mathrm{CNPq} / \mathrm{Brazil}$.

\section{Conflict of interest}

The authors declare no conflict of interest.

\section{References}

1. Boukhatem, M.N. et al. Lemon grass (Cymbopogon citratus) essential oil as a potent anti-inflammatory and antifungal drugs. 2014.p.25431.

2. Elansary, H. et al. Diversity of Plants, Traditional Knowledge, and Practices in Local Cosmetics: A Case Study from Alexandria, Egypt. New York: 2015.p.114126.

3. Farmacopéia Brasileira. 4.ed. São Paulo:1989.

4. Kerr, K.G. Molecular Microbiology. 2005.p.560.

5. Mittermeier, R. A. et al. A Brief History of Biodiversity Conservation in Brazil. Belo Horizonte:2005.p.601-607.

6. Munir, A. et al. Design, development and experimental results of a solar distillery for the essential oils extraction from medicinal and aromatic plants. 2014.p.548-559.

7. NCCLS (National Committee for Clinical Laboratory Standards) Methods for Dilution Antimicrobial Susceptibility Tests for Bacteria That Grow Aerobically. NCCLS document M7-A6,2003. Available at: $<$ http:

//www.sbac.org.br/pt/pdfs/biblioteca/clsi OPASM7_A6.pdf >. Accessed on: 06/06/2011.

8. Sartor, R.B. et al. Dynamic Simulation of Rosemary Essential Oil Extraction in an Industrial Steam Distillation Unit. Rio de Janeiro: 2011.p.3955-3959.

9. Sebaaly, C. et al. Preparation and characterization of clove essential oilloaded liposomes. 2015.p.52-62. 